\title{
Cognitive Function and Impairment in Older, Rural South African Adults: Evidence from "Health and Aging in Africa: A Longitudinal Study of an INDEPTH Community in Rural South Africa"
}

\author{
Lindsay C. Kobayashi ${ }^{a, b}$ Farrah J. Mateen ${ }^{c, d}$ Livia Montana $^{b}$ \\ Ryan G. Wagnere, ${ }^{\mathrm{f}}$ Kathleen Kahn ${ }^{\mathrm{b}, \mathrm{e}-\mathrm{g}}$ Stephen M. Tollman ${ }^{\mathrm{b}, \mathrm{e}-\mathrm{g}}$ \\ Lisa F. Berkman b, e \\ a Lombardi Comprehensive Cancer Center, Georgetown University, Washington, DC, USA; ${ }^{b}$ Harvard Center \\ for Population and Development Studies, Harvard T.H. Chan School of Public Health, Cambridge, MA, USA;

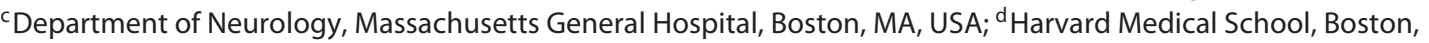

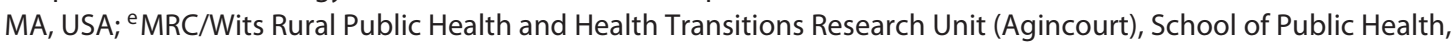 \\ Faculty of Health Sciences, University of the Witwatersrand, Johannesburg, South Africa; ${ }^{f}$ Centre for Global Health \\ Research, Umeå University, Umeå, Sweden; ' IINDEPTH Network, Accra, Ghana
}

\section{Keywords}

Africa $\cdot$ Age factors · Education · Cross-sectional studies · Epidemiology $\cdot$ Prevalence $\cdot$ Sex $\cdot$ Sociodemographic characteristics · Cognitive function - Cognitive impairment

\footnotetext{
Abstract

Background/Aims: We aimed to estimate the prevalence of cognitive impairment, and the sociodemographic and comorbid predictors of cognitive function among older, rural South African adults. Methods: Data were from a population-based study of 5,059 adults aged $\geq 40$ years in rural South Africa in 2015. Cognitive impairment was defined as scoring $\leq 1.5$ SDs below the mean composite time orientation and memory score, or requiring a proxy interview with "fair" or "poor" proxy-reported memory. Multiple linear regression estimated the sociodemographic and comorbid predictors of cognitive score, with multiplicative statistical interactions between each of age and sex with education.
}

Results: Cognitive impairment increased with age, from $2 \%$ of those aged $40-44(11 / 516)$ to $24 \%$ of those aged $\geq 75$ years (214/899). The independent predictors of lower cognitive score were being older, female, unmarried, not working, having low education, low household wealth, and a history of cardiovascular conditions. Education modified the negative associations between female sex, older age, and cognitive function score. Conclusions: The prevalence of cognitive impairment increased with age and is comparable to rates of dementia reported in other sub-Saharan African countries. Age and sex differences in cognitive function scores were minimized as education increased, potentially reflecting the power of even poor-quality education to improve cognitive reserve.

(c) 2018 S. Karger AG, Basel

This work was conducted at the Harvard Center for Population and Development Studies, Harvard T.H. Chan School of Public Health, Cambridge, MA, USA.

\section{KARGER}

(c) 2018 S. Karger AG, Basel

E-Mail karger@karger.com

www.karger.com/ned
Lisa F. Berkman

Harvard Center for Population and Development Studies

9 Bow Street

Cambridge, MA 02138 (USA)

E-Maillberkman@hsph.harvard.edu 


\section{Introduction}

The populations of most sub-Saharan African countries are rapidly aging. By 2050, 72 million people across sub-Saharan Africa are projected to experience Alzheimer's disease and related dementias (according to DSM-IV or ICD-10 criteria or similar clinical criteria, collectively referred to from hereon as "dementia"), an increase of $257 \%$ since 2015 [1]. Currently, there are very few population-based studies on the prevalence of dementia, cognitive impairment, or cognitive functioning in sub-Saharan African countries [1-16], a gap requiring urgent attention given the rapidly increasing life expectancies and projected rise of dementia in this global region. Population-based data on dementia, cognitive impairment, and cognitive functioning are needed to generate prevalence estimates, identify risk factors, and assist health systems, communities, and aid organizations in prioritizing resources to prevent and provide care for people with dementia in sub-Saharan Africa.

Here, we focus on South Africa, a country that is undergoing simultaneous demographic and epidemiologic transitions: the share of South Africa's population aged over 65 years is now larger than that aged under 5 years, and increasing incidence rates of chronic agingrelated conditions are coinciding with a high prevalence of chronic human immunodeficiency virus (HIV) infection [17-19]. South Africa experienced a period of apartheid from 1948 to 1994, which, by legislation, limited the geographic movement, educational opportunities, and employment opportunities for South Africans who were deemed to be non-white [20]. Apartheid and its earlier precursors have shaped the health of South Africa's older population in many ways, which are not yet completely understood [20-23]. In particular, cognitive function and impairment have been understudied in older, black South Africans who lived through apartheid, particularly those residing in rural regions [2].

In 2015, we launched "Health and Aging in Africa: A Longitudinal Study of an INDEPTH Community in South Africa" (HAALSI), a population-based study in the rural northeast of South Africa [24]. Here, using a screening tool adapted from the US Health and Retirement Study (HRS), we aimed to estimate the prevalence of cognitive impairment and the sociodemographic and key comorbid predictors of cognitive function in older, rural South African adults.

Cognitive Function and Impairment in

Older, Rural South African Adults

\section{Materials and Methods}

Study Design

"Health and Aging in Africa: A Longitudinal Study of an INDEPTH Community in South Africa" (HAALSI) is a population-based cohort of 5,059 adults aged $\geq 40$ years with an $86 \%$ response rate [24]. Here, we report on baseline cross-sectional findings collected in 2015. HAALSI is harmonized with the US HRS and is representative of the Agincourt Health and Socio-demographic Surveillance System Census of approximately 116,000 individuals living in Mpumalanga province, northeast South Africa $[24,25]$. In-person interviews were conducted by trained, local fieldworkers using computer-assisted personal interviews and blood was drawn for HIV status and biomarker ascertainment. All interview materials were translated to the local Shaangan language and back-translated, and pilot tested for accuracy, appropriateness, and comprehensibility in a sample of older local residents who did not become part of the HAALSI study population. Ethical approval was granted by the University of Witwatersrand Human Research Ethics Committee and the Harvard T.H. Chan Harvard School of Public Health Institutional Research Ethics Board. Each respondent or proxy respondent provided informed consent prior to being interviewed.

\section{Study Measures}

Cognitive Measures

A cognitive battery was administered, using measures adapted from the US HRS brief screening instrument for dementia [26, 27]. The cognitive battery assessed time orientation (ability to state the correct date, month, year, and South African President; 4 points total) and immediate and delayed recall of 10 words read out loud ( 1 point for each word; 20 points total). The cognitive function outcome was the total score out of 24 on the combined time orientation and immediate and delayed recall items. The cognitive battery also included 2 numeracy measures, which were not included in the present analysis as they are thought to reflect schooling more strongly than aging-related cognitive impairment.

Definition of Cognitive Impairment

We followed the method of Wu et al. [28] to categorize cognitive impairment, using a combination of cognitive battery scores and proxy memory assessments, which Wu et al. [28] developed and validated against DSM-diagnosed dementia in the Aging, Demographics, and Memory Study sub-study of the US HRS. We used the same cognitive battery and proxy memory assessments as those validated by Wu et al. [28] in the US HRS. Scores of $\leq 1.5$ SDs below the overall cognitive battery mean were considered to indicate cognitive impairment [29]. While we recognize that many respondents assigned to this category will, in fact, present with dementia, the lack of a clinical dementia rating or DSM diagnosis to validate our categorization means that we may lack specificity to identify dementia, and thus conservatively define our outcome as "cognitive impairment". A total of 116 participants had proxy interviews completed on their behalf by a friend or family member, due to their being cognitively or verbally unable to complete the study interview. Proxy respondents were asked to rate the incapacitated participant's memory on a 5-point Likert scale. In total, 32 rated the participant's memory as "poor" (28\%), 47 as "fair" 
(41\%), 28 as "good" (24\%), 8 as "very good" (7\%), and 1 did not know. The 79 participants whose memory was rated as "fair" or "poor" were included in the cognitive impairment group to reduce bias in study estimates that may be introduced by their exclusion [28].

Sociodemographic and Comorbidity Covariates

The following variables were selected in order to investigate sociodemographic patterning of cognitive function and its associated comorbidities: age $(40-44,45-49,50-54,55-59,60-64$, $65-69,70-74, \geq 75)$, sex (male; female), highest level of education (no formal education [0 years], some primary school [1-7 years], some secondary school or higher [8+ years]), marital status (married or cohabiting; single/divorced/widowed), employment status (working part-time or full-time; not working; homemaker), household wealth quintile; HIV infection status (negative; positive), hypertension (yes; no), and self-reported physician diagnosis of each of stroke, angina, or myocardial infarction (ever; never), and drinking alcohol $\geq 5$ days per week (yes; no). All variables were self-reported, except for HIV and hypertension. HIV status was determined through HIV enzyme-linked immunosorbent assays on dried blood spots as negative, positive, or missing, which included participant refusals and indeterminate tests. Hypertension was defined as a mean systolic blood pressure $>140$ $\mathrm{mm} \mathrm{Hg}$ or mean diastolic blood pressure $>90 \mathrm{~mm} \mathrm{Hg}$, or controlled blood pressure with self-reported use of hypertensive medication.

\section{Statistical Analyses}

The prevalence of cognitive impairment and the cognitive score means and standard deviations were calculated overall and according to covariates. We used multiple linear regression to estimate relationships between all covariates and total cognitive score. In 2 separate, fully-adjusted models, we fitted multiplicative statistical interactions between each of sex and education, and age and education. We then estimated the marginal effects of age and sex on mean fully adjusted predicted cognitive battery score over categories of educational attainment. Finally, we fitted a model with a 3-way multiplicative interaction between age, sex, and education, and from this model plotted the predicted values of cognitive battery score. The interaction analyses were conducted because the cognitive effects of education were hypothesized to differ according to sex and age in this study: accessibility and quality of education has improved over time for subsequent birth cohorts among black South Africans, although girls have been continually disadvantaged compared to boys with respect to educational access and quality [21,30-32]. Statistical analyses were conducted using SAS 9.4 (Cary, NC, USA) and StataSE 15.0 (College Station, TX, USA).

\section{Missing Data}

All proxy $(116 / 5,059)$ and non-proxy participants $(4,943 / 5,059)$ were included in the cognitive impairment estimate, except for 40 out of 4,943 non-proxy participants (3\%) who declined the cognitive battery, for a total of 5,019 out of 5,059 (99\%). Of the remaining 4,903 out of 4,943 non-proxy participants who completed the cognitive battery, 125 (3\%) were missing data on at least one covariate. Therefore, a total of 4,778 out of 4,943 non-proxy participants $(97 \%)$ were included in the analytical sample for regression modeling. The non-proxy participants who were not included in regression modeling were similar on all characteristics, but were slightly more likely to be male than female ( $4 \%$ of males vs. $3 \%$ of females missing data).

\section{Results}

The mean cognitive score was 11.40 (SD 4.45; range $0-24$; Table 1$)$. In total, 416 out of 5,059 participants $(8 \%)$ were categorized as having cognitive impairment, 337 were on the basis of scoring $\leq 1.5 \mathrm{SD}$ below the mean cognitive score, and 79 were proxy respondents with "fair" or "poor" memory. The prevalence of cognitive impairment increased with age, from $2 \%$ of those aged $40-44$ to $24 \%$ of those aged $\geq 75$ years. Of the non-proxy participants with cognitive impairment, $87 \%$ (294/337) scored either 0 or 1 on the time orientation items (knowledge of the correct date, month, year, and President) and 44\% (148/337) rated their memory as "fair" or "poor." The cognitive scores were normally distributed, similar to those observed in the HRS, although the HAALSI distribution was shifted to the left of the HRS distribution (online supplementary Appendix; see www.karger.com/doi/10.1159/000493483).

The independent predictors of cognitive score (out of 24 points) are shown in Table 2 . Older age was negatively associated with cognitive score $(-0.45$ points per 5 years of age; $95 \% \mathrm{CI}-0.51$ to -0.39$)$, and females had lower average scores than males $(-0.18$ points; $95 \%$ CI -0.42 to 0.06). Cognitive scores increased with educational attainment; adults with some secondary education or higher scored, on average, 3.05 points (95\% CI 2.69-3.30) higher than those with no formal education (Table 2). Being HIV positive or hypertensive were associated with higher cognitive scores, while having a history of physician-diagnosed stroke, angina, or heart attack was associated with lower cognitive score (Table 2).

The negative association between age and cognitive score decreased in magnitude with increasing levels of education, from -0.54 ( $95 \% \mathrm{CI}-0.62$ to -0.46$)$ per 5 years of age in adults with no formal education to -0.40 (95\% CI -0.53 to -0.26 ) in those with secondary education or higher (Table 3). Similarly, being female was negatively associated with cognitive score for adults with no formal education $(-0.72 ; 95 \%$ CI -1.06 to -0.37$)$, but there were no sex differences in cognitive scores for adults who had any level of education (Table 3). When a 3-way multiplicative interaction between age, sex, and education was fitted, the negative slope of cognitive change with increasing age was steeper at each level of educational attainment for females than for males (Fig. 1). 
Table 1. Sample Characteristics, "Health and Aging in Africa: a longitudinal study of an INDEPTH community in South Africa"

\begin{tabular}{|c|c|c|c|}
\hline Characteristic & $\begin{array}{l}\text { Total } *, n(\%) \\
5,059 / 5,059(100 \%)\end{array}$ & $\begin{array}{l}\text { Mean cognitive score }{ }^{\dagger} \\
11.41(4.45)\end{array}$ & $\begin{array}{l}\text { Cognitive impairment }{ }^{\ddagger}, n(\%) \\
416 / 5,019(8 \%)\end{array}$ \\
\hline \multicolumn{4}{|l|}{ Age, years } \\
\hline $45-49$ & $399(8)$ & $13.25(3.79)$ & $9(2)$ \\
\hline $50-54$ & $783(15)$ & $12.84(4.30)$ & $31(4)$ \\
\hline $55-59$ & $627(12)$ & $12.01(4.04)$ & $24(4)$ \\
\hline $70-74$ & $514(10)$ & $10.03(3.88)$ & $49(10)$ \\
\hline $75+$ & $913(18)$ & $8.27(4.30)$ & $214(24)$ \\
\hline \multicolumn{4}{|l|}{ Gender } \\
\hline Male & $2,345(46)$ & $11.73(4.40)$ & $163(7)$ \\
\hline Female & $2,714(54)$ & $11.13(4.48)$ & $253(9)$ \\
\hline \multicolumn{4}{|l|}{ Employment status } \\
\hline Employed (part- or full-time) & $805(16)$ & $13.65(4.24)$ & $14(2)$ \\
\hline Not working & $3,719(74)$ & $10.90(4.41)$ & $369(10)$ \\
\hline Homemaker & $521(10)$ & $11.47(3.94)$ & $32(6)$ \\
\hline \multicolumn{4}{|l|}{ Marital status } \\
\hline Married & $2,575(51)$ & $12.19(4.20)$ & $105(4)$ \\
\hline Unmarried & $2,480(49)$ & $10.57(4.56)$ & $311(13)$ \\
\hline \multicolumn{4}{|l|}{ Household wealth quintile } \\
\hline 5 (richest) & $1,046(21)$ & $12.96(4.24)$ & $36(4)$ \\
\hline 4 & $1,001(20)$ & $11.71(4.47)$ & $73(7)$ \\
\hline 3 & $991(20)$ & $11.41(4.22)$ & $71(7)$ \\
\hline 2 & $1,007(20)$ & $10.78(4.34)$ & $103(10)$ \\
\hline \multicolumn{4}{|l|}{ Ever stroke, angina, or heart attack } \\
\hline No & $4,786(95)$ & $11.47(4.45)$ & $377(8)$ \\
\hline Yes & $269(5)$ & $10.22(4.28)$ & $37(14)$ \\
\hline \multicolumn{4}{|l|}{ Alcohol consumption $\leq 5$ days/week } \\
\hline No & $4,751(94)$ & $11.46(4.41)$ & $377(8)$ \\
\hline Yes & $304(6)$ & $10.61(5.00)$ & $38(13)$ \\
\hline
\end{tabular}

* Numbers in rows may not sum to 5,059 due to missing data; ${ }^{\dagger}$ proxy study participants are excluded from the mean cognitive battery scores; ${ }^{\ddagger}$ defined as scoring $\leq 1.5$ SD below the mean on the time orientation and word recall measures, or requiring a proxy interview with "fair" or "poor" memory as rated by the proxy respondent.

\section{Discussion}

In this population-based study of rural South African adults aged 40 years and over, approximately $8 \%$ of the sample were estimated to have cognitive impairment.
Cognitive impairment increased with age, from $2 \%$ of those aged $40-44$ years to $24 \%$ of those aged $\geq 75$ years. The key predictors of poor cognitive function were sociodemographic in nature. The associations with HIV status and hypertension were of weaker magnitudes and 
Table 2. Linear regression model predicting total cognitive score, "Health and Aging in Africa: a longitudinal study of an INDEPTH Community in South Africa," South Africa, 2015 ( $n=4,778)$

\begin{tabular}{|c|c|c|c|}
\hline \multirow[t]{2}{*}{ Characteristic } & \multicolumn{3}{|c|}{ Linear regression predicting total cognitive score } \\
\hline & $\mathrm{B}$ & $95 \% \mathrm{CI}$ & SE \\
\hline \multicolumn{4}{|l|}{ Age, years } \\
\hline Per 5 years & -0.45 & -0.51 to -0.39 & 0.03 \\
\hline \multicolumn{4}{|l|}{ Gender } \\
\hline Male & Ref & - & - \\
\hline Female & -0.18 & -0.42 to 0.06 & 0.12 \\
\hline \multicolumn{4}{|l|}{ Educational attainment } \\
\hline No education & Ref & - & - \\
\hline Some primary ( $1-7$ years) & 1.94 & 1.69 to 2.20 & 0.13 \\
\hline Some secondary or higher $(8+$ years $)$ & 3.05 & 2.69 to 3.30 & 0.18 \\
\hline \multicolumn{4}{|l|}{ Employment status } \\
\hline Employed (part- or full-time) & Ref & - & - \\
\hline Not working & -0.64 & -0.97 to -0.32 & 0.17 \\
\hline Homemaker & 0.02 & -0.43 to 0.47 & 0.23 \\
\hline \multicolumn{4}{|l|}{ Marital status } \\
\hline Married or living as married & Ref & - & - \\
\hline Single/divorced/widowed & -0.89 & -1.13 to -0.65 & 0.12 \\
\hline \multicolumn{4}{|l|}{ Household wealth quintile } \\
\hline 5 (richest) & Ref & - & - \\
\hline 4 & -0.56 & -0.90 to -0.21 & 0.18 \\
\hline 3 & -0.60 & -0.95 to -0.25 & 0.18 \\
\hline 2 & -0.87 & -1.23 to -0.51 & 0.18 \\
\hline 1 (poorest) & -1.12 & -1.50 to -0.76 & 0.19 \\
\hline \multicolumn{4}{|l|}{ HIV infection status } \\
\hline Negative & Ref & - & - \\
\hline Positive & 0.47 & 0.19 to 0.76 & 0.14 \\
\hline Missing & 0.15 & -0.26 to 0.56 & 0.21 \\
\hline \multicolumn{4}{|l|}{ Hypertension } \\
\hline No & Ref & - & - \\
\hline Yes & 0.36 & 0.13 to 0.58 & 0.12 \\
\hline \multicolumn{4}{|l|}{ Ever stroke, angina, or heart attack } \\
\hline No & Ref & - & - \\
\hline Yes & -0.68 & -1.17 to -0.17 & 0.25 \\
\hline \multicolumn{4}{|l|}{ Alcohol consumption $\geq 5$ days/week } \\
\hline No & Ref & - & - \\
\hline Yes & -0.31 & -0.77 to 0.16 & 0.24 \\
\hline
\end{tabular}

in the unexpected positive directions, which may be due to selective HIV infection and survival prior to the study entry, differential access to care, or other pathways that require further investigation. Further longitudinal findings may shed more light on these associations. The lower cognitive scores observed among females compared to males with no formal education was completely negated among older adults who had at least some education. These findings suggest that even the poor-quality education that was available to this study population under apartheid may have positively affected later-life cognitive function, and that sex disparities in later-life cognitive functioning are restricted to older adults who had no formal education. These findings are a valuable baseline "snapshot" of cognitive function and impairment in the older population of rural, northeast South Africa. Future follow-ups that are underway in this cohort will build upon these baseline results, with clinical dementia ratings based on neuroimaging, expert review, and exclusion of competing diagnoses. 
Table 3. Marginal effects of age and sex on cognitive score over education categories, "Health and Aging in Africa: a longitudinal study of an INDEPTH Community in South Africa," South Africa, $2015(n=4,778)$

\begin{tabular}{|c|c|c|c|}
\hline \multirow[t]{2}{*}{ Characteristic } & \multicolumn{3}{|c|}{ Linear regression predicting total cognitive score } \\
\hline & $\beta$ & $95 \% \mathrm{CI}$ & SE \\
\hline \multicolumn{4}{|l|}{ Age (per 5 years $) \times$ education } \\
\hline No education & -0.54 & -0.62 to -0.46 & 0.04 \\
\hline Some primary ( $1-7$ years) & -0.37 & -0.46 to -0.28 & 0.05 \\
\hline Some secondary or higher $(8+$ years $)$ & -0.40 & -0.53 to -0.26 & 0.07 \\
\hline \multicolumn{4}{|l|}{ Gender $($ female vs. male) $\times$ education } \\
\hline No education & -0.72 & -1.06 to -0.37 & 0.18 \\
\hline Some primary ( $1-7$ years) & 0.28 & -0.10 to 0.66 & 0.19 \\
\hline Some secondary or higher $(8+$ years $)$ & 0.15 & -0.33 to 0.64 & 0.25 \\
\hline
\end{tabular}

Adjusted for employment status, marital status, household wealth quintile, HIV infection status, hypertension, history of stroke/angina/heart attack, and alcohol consumption.

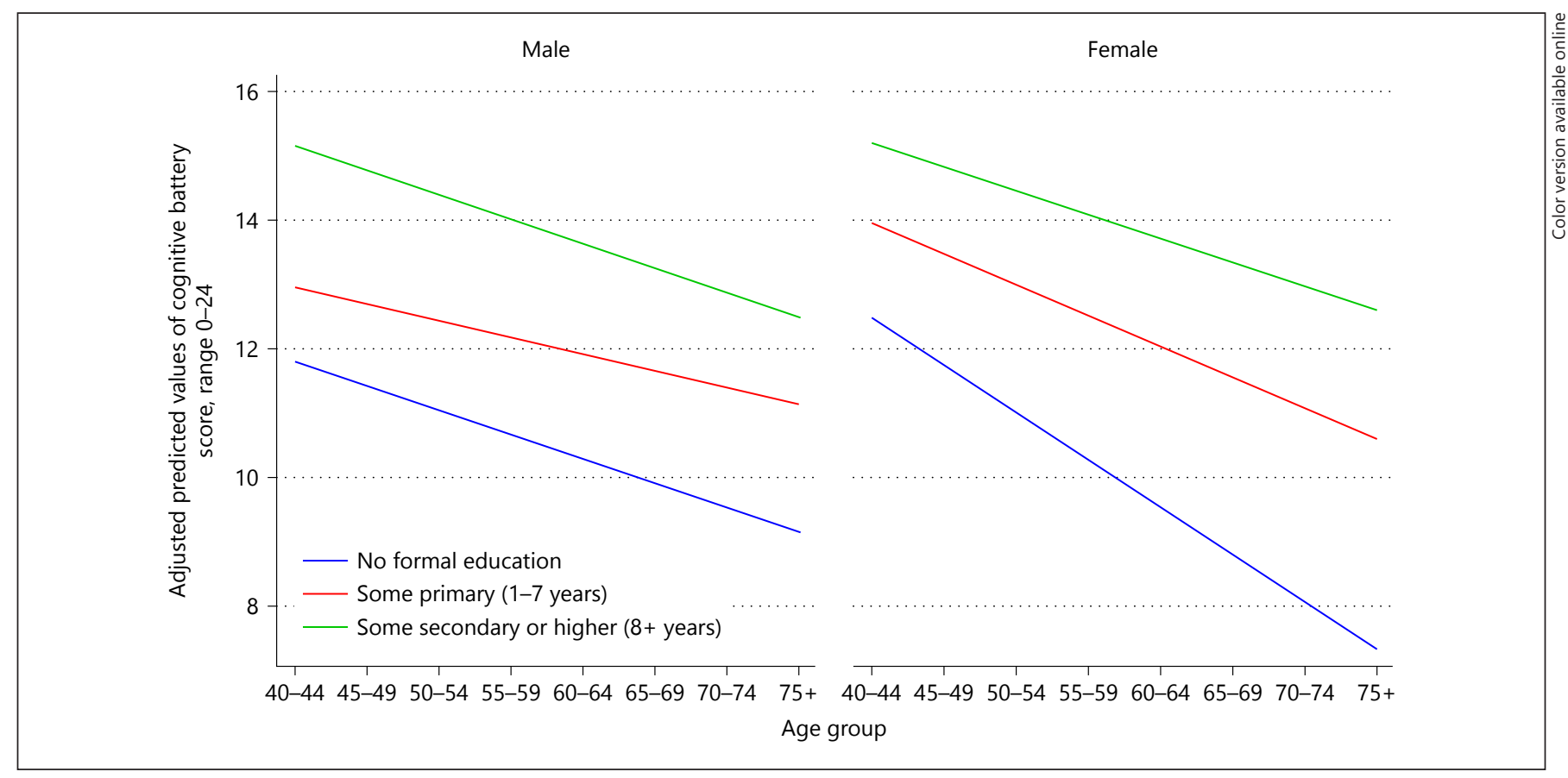

Fig. 1. Fully adjusted predicted mean cognitive scores $(n=4,778)$.

\section{Comparison to Other Research}

Very little research has investigated the prevalence of cognitive impairment or dementia in sub-Saharan Africa. Lekoubou et al. [4] 2014 systematic review of dementia prevalence studies in sub-Saharan Africa retrieved 49 studies, many of which utilized hospital-based samples and only one of which was conducted in South Africa, in an urban community of 139 "coloured" adults in 1983, with $9 \%$ dementia prevalence according to
MMSE/ICD-8 codes [33]. A total of 10 prevalence studies with a DSM-III/-IV outcome of dementia were identified for sub-Saharan Africa in a 2017 Alzheimer's Disease International report, with a pooled prevalence of $5.50 \%$ of adults aged $\geq 60$; the pooled prevalence for women was approximately double that for men for all age groups $[1,2]$. We found a slightly higher prevalence of cognitive impairment in our study of $8.22 \%$ of adults aged $\geq 40$; this could be due to an overestimate of 
the people or possibility due to differences in sample composition. We identified one other population-based study of dementia prevalence in rural South Africa among 1,394 Xhosa-speaking adults $\geq 60$ in the Eastern Cape, which found a prevalence of $12 \%$ according to the Community Screening Instrument for Dementia but did not observe gender-based or educational differences in dementia prevalence [8].

In Lekoubou et al. [4] systematic review, the most consistent risk factors for dementia incidence in older sub-Saharan African adults were older age, female sex or gender, having less than 6 years of education, rural residence, and family history of dementia. Most studies included in this review were conducted in Nigeria, and rural South Africa was not represented. In South Africa, the nationally representative Study of Global Ageing and Adult Health of 3,840 adults $\geq 50$ in 2008 found that better memory and executive functioning scores were associated with being younger, male, of a white or Indian/Asian/colored ethnicity, married, having higher education, and having greater wealth [7]. These findings are consistent with those presented here for a rural cohort of older black South Africans. Overall, it appears that being older, being female, and having low education are consistently and strongly associated with poor cognitive function and dementia in older sub-Saharan African populations. This is consistent with a large body of evidence from high-income Western countries, although the associations between sex or gender and cognitive function are somewhat inconsistent $[27,28$, 33-37].

\section{Strengths and Limitations}

Strengths of this study include its population-based design with a high response rate and low rate of missing data. Our study population is broadly representative of older, black populations in low-income rural regions of South Africa [38]. Given that life expectancy at birth in South Africa is currently only 60.6 years for men and 64.3 years for women [39], the HAALSI cohort represents some of the "oldest-old" black, rural South Africans, a population that is understudied with respect to health outcomes. Our cognitive measures included were adapted from validated measures, and translated and back-translated to ensure cultural appropriateness and reliability in the local Shangaan language. The relatively high number of older adults with no formal education in this study allowed us to examine age- and sexbased-differences in cognitive function by educational category, giving evidence from a setting where many people could not access schooling. Overall, the HAALSI cohort is a unique and valuable data resource that allows for the investigation of health outcomes in the understudied older population of rural South Africa in the midst of an epidemiological and demographic transition.

There are also several limitations of our study. Age, period, and cohort effects could not be separated, as it was a cross-sectional analysis of baseline data. The age differences in cognitive function and impairment that we observed may, at least in part, reflect improved educational quality over time across the 20th century for black South Africans rather than cognitive aging processes. We did not have a physician-diagnosed outcome of dementia, and therefore our prevalence estimate must be thought of as "cognitive impairment." This outcome will certainly include people with dementia, as well as those who are cognitively impaired for reasons other than a dementia or other neurodegenerative disorder. For example, sensory impairments or psychiatric conditions could negatively affect performance on a cognitive battery, independently of dementia. There remains no consensus on the best method to test cognitive function and screen for dementia in sub-Saharan African populations. Most existing screening measures have been developed for relatively well-educated Western, high-income populations, and differences in language, literacy, education, and culture are difficult to overcome in adapting measures. Here, we used a validated and well-accepted brief screening tool for dementia adapted from the US HRS that lacked floor or ceiling effects. The study participants who were categorized as having cognitive impairment overwhelmingly failed or scored a single point on the time orientation measure and half had "fair" or "poor" self-rated memory.

\section{Conclusions}

There are currently very few population-based studies of cognitive impairment, dementia, or cognitive function in sub-Saharan African regions. HAALSI is one of the few studies to examine cognitive function among older adults in post-apartheid rural South Africa. Using a brief screening tool adapted from the US HRS, we found that the prevalence of cognitive impairment rises from $2 \%$ of adults aged $40-44$ to $24 \%$ of those aged 75+ years in rural South Africa. Further, being older, female, and having a lack of education are key predictors of poor cognitive function in this population.
38

Neuroepidemiology 2019;52:32-40 DOI: $10.1159 / 000493483$
Kobayashi/Mateen/Montana/Wagner/ Kahn/Tollman/Berkman 
Longitudinal follow-up of the HAALSI cohort begins in 2018 , and future dementia prevalence estimates will use a clinical dementia rating based on neuroimaging, expert review, and exclusion of competing diagnoses, in addition to a novel tablet assessment of cognitive function that minimally involves literacy or language skills [40]. The findings presented here are a valuable baseline for future longitudinal research within HAALSI and other research on aging in rural, sub-Saharan African contexts.

\section{Acknowledgements and Funding Source}

We thank Dr. Elyse Jennings, $\mathrm{PhD}$ for her valuable contributions to this manuscript, and Ms. Sara Grundy, BA, for her assistance with manuscript preparation. This work was supported by the U.S. National Institute on Aging (P01AG041710; 1R01AG051144-01; 3U54HG006938-03S1) and the Agincourt Health and Demographic Surveillance System supported by the University of the Witwatersrand and Medical Research Council, South Africa, the Wellcome Trust, UK (grants 058893/Z/99/A; 069683/Z/02/Z; 085477/Z/08/Z; 085477/B/08/Z). F. Mateen was supported by a sub-grant of P30AG024409.

\section{References}

1 Guerchet M, Mayston R, Lloyd-Sherlock P, Prince M, Aboderin I, Akinyemi R, et al: Dementia in Sub-Saharan Africa: Challenges and Opportunities. London, 2017.

2 Prince M, Wimo A, Guerchet M, Ali GC, Wu YT, Prina M, et al: World Alzheimer Report 2015: The Global Impact of Dementia: An Analysis of Prevalence, Incidence, Cost, and Trends. London, 2015.

3 de Jager CA, Joska JA, Hoffman M, Borochowitz KE, Combrinck MI: Dementia in rural South Africa: A pressing need for epidemiological studies. S Afr Med J 2015;105:189-190.

4 Lekoubou A, Echouffo-Techeugui JB, Kengne AP: Epidemiology of neurodegenerative diseases in sub-Saharan Africa: a systematic review. BMC Public Health 2014;14:653.

5 Mavrodaris A, Powell J, Thorogood M: Prevalences of dementia and cognitive impairment among older people in sub-Saharan Africa: a systematic review. Bull World Health Organ 2013;91:773-783.

6 Olayinka OO, Mbuyi NN: Epidemiology of dementia among the elderly in sub-Saharan Africa epidemiology of dementia among the Elderly in Sub-Saharan Africa. Int J Alzheimers Dis 2014;2014:195750.

7 Peltzer K, Phaswana-Mafuya N: Cognitive functioning and associated factors in older adults in South Africa. S Afr J Psychiatr 2012, 18:157-163.

8 De Jager CA, Msemburi W, Pepper K, Combrinck MI: Dementia prevalence in a rural region of South Africa: a cross-sectional community study. J Alzheimers Dis 2017;60: 1087-1096.

9 Longdon AR, Paddick SM, Kisoli A, Dotchin C, Gray WK, Dewhurst F, et al: The prevalence of dementia in rural Tanzania: a crosssectional community-based study. Int J Geriatr Psychiatry 2013;28:728-737.

10 Paddick SM, Longdon AR, Kisoli A, Dotchin C, Gray WK, Dewhurst F, et al: Dementia prevalence estimates in sub-Saharan Africa: comparison of two diagnostic criteria. Glob Health Action 2013;6:19646.

11 Paddick SM, Longdon A, Kisoli A, Gray WK, Dotchin CL, Jusabani A, et al: The prevalence of dementia subtypes in rural Tanzania. Am J Geriatr Psychiatry 2014;22:1613-1622.

12 Paraiso MN, Guerchet M, Saizonou J, Cowppli-Bony P, Mouanga AM, Nubukpo P, et al: Prevalence of dementia among elderly people living in Cotonou, an urban area of benin (West Africa). Neuroepidemiology 2011;36: 245-251.

13 Guerchet M, Mbelesso P, Ndamba-Bandzouzi B, Pilleron S, Desormais I, Lacroix P, et al: Epidemiology of dementia in Central Africa (EPIDEMCA): protocol for a multicentre population-based study in rural and urban areas of the Central African Republic and the Republic of Congo. Springerplus 2014;3: 338.

14 Preux PM, Guerchet M, EPIDEMCA: Epidemiolocy of dementia in sub-saharan Africa. Bull Acad Natl Med 2015;199:1187-1197.

15 Pilleron S, Jésus P, Desport JC, Mbelesso P, Ndamba-Bandzouzi B, Clément JP, et al: Association between mild cognitive impairment and dementia and undernutrition among elderly people in Central Africa: some results from the EPIDEMCA (epidemiology of dementia in Central Africa) programme. Br J Nutr 2015;114:306-315

16 Pilleron S, Guerchet M, Ndamba-Bandzouzi B, Mbelesso P, Dartigues JF, Preux PM, et al: Association between stressful life events and cognitive disorders in Central Africa: results from the EPIDEMCA Program. Neuroepidemiology 2015;44:99-107.

17 Kabudula CW, Tollman S, Mee P, Ngobeni S, Silaule B, Gómez-Olivé FX, et al: Two decades of mortality change in rural northeast South Africa. Glob Health Action 2014;7.

18 Kabudula CW, Houle B, Collinson MA, Kahn K, Gómez-Olivé FX, Clark SJ, et al: Progression of the epidemiological transition in a rural South African setting: findings from population surveillance in Agincourt, 1993-2013. BMC Public Health 2017; 17:424.

19 Tollman SM, Norris SA, Berkman LF: Commentary: The value of life course epidemiology in low- and middle-income countries: an ageing perspective. Int J Epidemiol 2016;45: 997-999.
20 United Nations: Apartheid in South Africa: Summary of the Report of the Special Committee on the Policies of Apartheid of the Government of South Africa. New York, United Nations, 1963, p 47.

21 United Nations Centre Against Apartheid. The effects of apartheid on the status of women in South Africa Black Scholar 1978;10:1120.

22 Hosegood V, Timaeus IM: HIV/AIDS and older people in South Africa; In Cohen B, Menken J (eds): Aging in Sub-Saharan Africa: Recommendations for Furthering Research. Washington, National Academies Press, 2006, pp 250-275.

23 Mayosi BM, Benatar SR: Health and health care in South Africa - 20 years after mandela. N Engl J Med 2014;371:1344-1353.

24 Gómez-Olivé FX, Montana L, Wagner RG, Kabudula CW, RohrJK, Kahn K, et al: Cohort profile: health and ageing in Africa: a longitudinal study of an INDEPTH community in South Africa (HAALSI). Int J Epidemiol 2018;1-12.

25 Kahn K, Collinson MA, Gómez-Olivé FX, Mokoena O, Twine R, Mee P, et al: Profile: agincourt health and socio-demographic surveillance system. Int J Epidemiol 2012;41: 988-1001.

26 Ofstedal MB, Fisher GG, Herzog AR, HRS Health Working Group: Documentation of cognitive functioning measures in the Health and Retirement Study. Ann Arbor 2005.

27 Sonnega A, Faul Jd, Ofstedal MB, Langa KM, Philips JW, Weir DR: Cohort profile: the health and retirement study (HRS). Int J Epidemiol 2014;43:576-585.

$28 \mathrm{Wu} \mathrm{Q}$, Tchetgen Tchetgen EJ, Osypuk TL, White K, Mujahid M, Maria Glymour M: Combining direct and proxy assessments to reduce attrition bias in a longitudinal study. Alzheimer Dis Assoc Disord 2013;27:207212

29 Langa KM, Larson EB, Karlawish JH, Cutler DM, Kabeto MU, Kim SY, et al: Trends in the prevalence and mortality of cognitive impairment in the United States: is there evidence of a compression of cognitive morbidity? Alzheimers Dement 2008;4:134-144.
Cognitive Function and Impairment in Older, Rural South African Adults
Neuroepidemiology 2019;52:32-40 DOI: $10.1159 / 000493483$ 
30 Unterhalter E: The impact of apartheid on women's education in south Africa. Rev Afr Polit Econ 1990;48:66-70.

31 Fiske EB, Ladd HF. Education and Apartheid. In: Fiske EB, Ladd HF (eds): Elusive Equity: Education Reform in Post-Apartheid South Africa. Washington, Brookings Institution Press, 2004, pp 40-60.

32 MATRIX: The Center for Humane Arts Letters and Social Sciences Online. Bantu Education. South Africa: Overcoming Apartheid, Building Democracy. 2017. http://overcomingapartheid.msu.edu/sidebar.php?id=65-258-2 (cited May 2, 2018).

33 Ben-Arie O, Swartz L, Teggin AF, Elk R: The coloured elderly in cape town-a psychosocial, psychiatric and medical community survey. Part II. Prevalence of psychiatric disorders. S Afr Med J 1983;64:1056-1061.
34 Cadar D, Robitaille A, Clouston S, Hofer SM, Piccinin AM, Muniz-Terrera G: An International evaluation of cognitive reserve and memory changes in early old age in 10 European Countries. Neuroepidemiology 2017;48: 9-20.

35 Lin KA, Choudhury KR, Rathakrishnan BG, Marks DM, Petrella JR, Doraiswamy $\mathrm{P}$ : Marked gender differences in progression of mild cognitive impairment over 8 years. Alzheimers Dement (N Y) 2015;1: 103-110.

36 Lindsay J, Laurin D, Verreault R, Hébert R, Helliwell B, Hill GB, et al: Risk factors for Alzheimer's disease: a prospective analysis from the Canadian study of health and aging. Am J Epidemiol 2002;156:445-453.

37 Weden MM, Shih RA, Kabeto MU, Langa KM: Secular trends in dementia and cogni- tive Impairment of U.S. rural and urban older adults. Am J Prev Med 2018;54:164172 .

38 Statistics South Africa. Vulnerable Groups Series II: The Social Profile of Older Persons, 2011-2015. Pretoria, Statistics South Africa, 2017, p 112.

39 Statistics South Africa: Mid-Year Population Estimates. Pretoria, Statistics South Africa, 2015, p 18 p.

40 Humphreys GW, Duta MD, Montana L, Demeyere N, McCrory C, Rohr J, et al: Cognitive function in low-income and low-literacy settings: validation of the tablet-based oxford cognitive screen in the health and aging in Africa: a longitudinal study of an INDEPTH community in South Africa (HAALSI). J Gerontol B Psychol Sci Soc Sci 2017;72: 38-50. 